\title{
СООБЩЕНИЯ
}

DOI: http://doi.org/10.15688/nav.jvolsu.2016.1.9

UDC 903(470.45/6)

LBC 63.48(235.54)-41

\section{NEW OBJECTS OF POTTERY PRODUCTION ON THE SUVOROVSKAYA I SITE (EXCAVATION MATERIALS OF 2012)}

\author{
Yakov A. Kiyashko \\ Volgograd State University, Volgograd, Russian Federation
}

\begin{abstract}
This article is devoted to the review of the results which were received after archaeological excavations in 2011-2012 on the site of Saltovo-Mayaki culture near Suvorovskaya village of the Volgograd region. The work gives the description of two pottery kilns which were found during the archeological excavations and had not been published before. The following research of pottery centers is very important for the reconstruction of social, economical and ethnocultural processes in Khazar Khanate.
\end{abstract}

Key words: the early Middle Ages, Khazar Khanate, Saltovo-Mayaki culture, the Lower Don, pottery production.

УДК 903(470.45/6)

ББК 63.48(235.54)-41

\section{НОВЫЕ ОБЬЕКТЫ ГОНЧАРНО-РЕМЕСЛЕННОГО ПРОИЗВОДСТВА НА ПАМЯТНИКЕ СУВОРОВСКАЯ І (ПО МАТЕРИАЛАМ РАСКОПОК 2012 Г.)}

\section{Яков Алексеевич Кияшко}

Волгоградский государственный университет, г. Волгоград, Российская Федерация

\begin{abstract}
Аннотация. В статье дан обзор некоторым результатам археологических работ в 2011-2012 гг. на памятнике салтово-маяцкой культуры у станицы Суворовская Волгоградской области. В работе приводится информация о двух гончарно-ремесленных горнах, которые были открыты в ходе археологических раскопок и ранее не публиковались. Исследование гончарно-ремесленных комплексов позволяет по-новому взглянуть на социально-экономические процессы, происходившие внутри Хазарского каганата.

Ключевые слова: эпоха раннего средневековья, Хазарский каганат, салтово-маяцкая культура, Нижний Дон, гончарно-ремесленное производство.
\end{abstract}

Целью данной работы является введение в научный оборот двух гончарно-ремесленных горнов, которые были исследованы на памятнике салтово-маяцкой культуры у станицы Суворовской Суровикинского района Волгоградской области.

Данный памятник был открыт экспедицией во главе с И.И. Ляпушкиным в ходе разведывательных работ по выявлению объек- тов культурного наследия, находящихся в зоне сооружения Цимлянского водохранилища. В процессе археологических раскопок, которые были предприняты археологами вышеуказанной экспедиции, было зафиксировано три гончарно-обжигательных печи, а также хозяйственные постройки, которые были интерпретированы как полуземлянки. Найденный керамический материал позволил отне- 
сти памятник к салтово-маяцкой археологической культуре и датировать его VIII-IX вв. [Ляпушкин, 1958, с. 336].

В 2011-2012 гг. автором данной заметки были возобновлены археологические работы на памятнике. Основным результатом полевых исследований является открытие в югозападной части памятника двух гончарно-обжигательных горнов, а также места сброса бракованной керамической продукции [Кияшко, 2016]. При этом в ходе визуального осмотра береговой полосы в юго-восточной части памятника были зафиксированы остатки топочной камеры еще одного горна, которые хорошо просматривались в обрезе береговой полосы. К сожалению, данный объект практически полностью был уничтожен вследствие обрушения берега.

Исходя из полученной информации, было решено заложить небольшой раскоп на данном участке с целью выявления возможных объектов, которые могут находиться под угрозой разрушения. В результате раскопок были обнаружены два гончарно-ремесленных горна, располагавшихся в непосредственной близости друг от друга и имевших одну общую рабочую площадку (см. рисунок).

Гончарно-обжигательный горн № 3 (нумерация сохраняется с учетом открытых горнов в юго-западной части памятника) был вырыт в материковом суглинке и состоял из двух частей - топки и обжигательной камеры. Топка одноканальная, без опорного столба, в плане имеет подгрушевидную форму. Обжигательная камера была разрушена вследствие проседания ее в топочную камеру. В связи с этим проследить границы обжигательной камеры не удалось. Сам горн ориентирован по линии ЮВ-СЗ. Размер пода топки по линии С-Ю-1,2 м; по линии 3-В - 1,15 м. Обжигательная камера располагалась над топкой. Стены и под камеры были, по всей видимости, хорошо обмазаны. Толщина обмазки составляет примерно 2 см. На сохранившихся экземплярах перекрытия - следы продухов, которые соединяли верхнюю и нижнюю часть горна. Устье горна выходило на небольшую предпечную площадку. Длина устья 0,6 м, ширина $-0,5$ м, высота - 0,5 м.
В заполнении горна присутствует большое количество керамики, фрагменты которой указывают на известные категории салтово-маяцкой посуды: серолощеные кувшины и кухонные горшки с линейно-волнистым орнаментом по тулову сосуда (см. рисунок).

Гончарно-обжигательный горн № 4 находился в полуметре от описанного выше объекта. Он также имеет двухъярусную конструкцию без опорного столба и вырыт в материковом суглинке. Обжигательная камера обрушилась в топочную часть, возможно, из-за канавы позднего времени, которая была зафиксирована в юго-восточной части горна. Ширина канавы 0,5 м, она разрезает объект по линии В-3. Исходя из сохранившихся стенок топочной камеры, можно заключить, что горн ориентирован по линии ЮЗ-СВ и устьем выходит на ту же предпечную площадку, что и горн № 3. Размер пода топки по линии С-Ю - 1,25 м; по линии 3-В - 1,2 м. Длина устья горна $-0,8$ м, ширина $-0,5$, высота 0,4 м. В заполнении встречены фрагменты салтово-маяцкой керамики и части обмазки, которой покрывались стены и под обжигательной камеры.

Стоит отметить, что вышеописанные гончарно-обжигательные горны по конструкции аналогичны объектам, которые были исследованы ранее на данном памятнике. Их разрушение, по всей видимости, является следствием существования на данном месте казачьего хутора в первой половине XX века. На это также указывают следы некогда существовавших хозяйственных построек, которые хорошо выделяются на поверхности поселения.

Таким образом, на памятнике у станицы Суворовской за все время исследования зафиксировано уже восемь гончарных горнов, некоторые из них имеют общую предпечную площадку. Высокая концентрация данных объектов подтверждает тезис о ремесленной специализации поселения Суворовская I. Это, в свою очередь, указывает на существование гончарно-ремесленных центров на территории распространения салтово-маяцкой археологической культуры. 


\section{ИЛЛЮСТРАЦИИ}

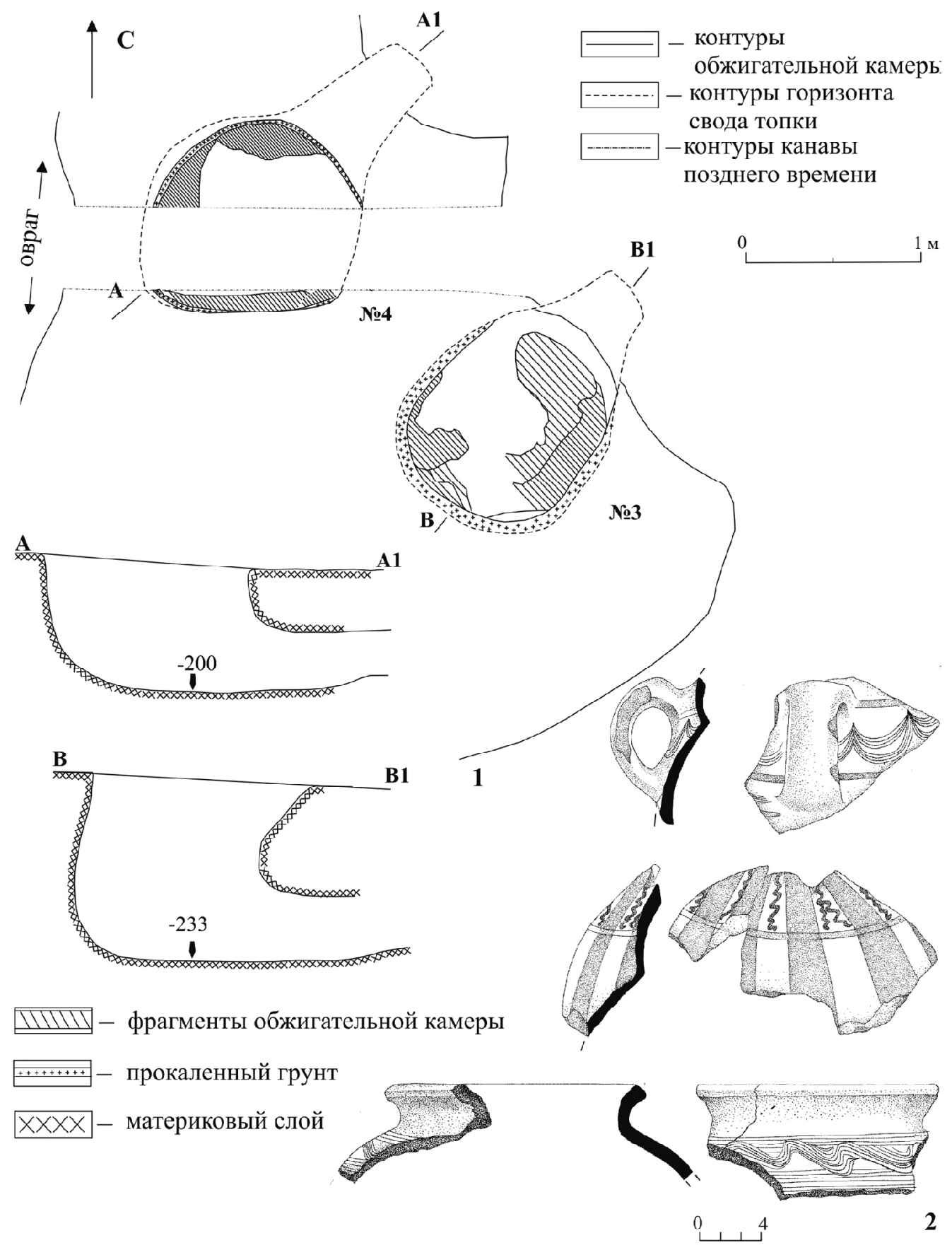

Планы гончарных горнов, открытых у станицы Суворовской (1), и фрагменты керамики из горнов (2) 
Ya.A. Kiyashko. New Objects of Pottery Production on the Suvorovskaya I Site

СПИСОК ЛИТЕРАТУРЫ

Кияшко Я. А. (2016). Гончарно-ремесленный центр у станицы Суворовской // Вестник Волгоградского государственного университета. Серия 4 , История. Регионоведение. Международные отношения. № 3. С. 14-24. DOI: 10.15688/jvolsu4.2016.3.2.

Ляпушкин И. И. (1958). Средневековое поселение близ ст. Суворовской // Материалы и исследования по археологии. № 62. С. 323-336.

\section{REFERENCES}

Kiyashko Y.A. (2016). The pottery center near Suvorovskaya village. Science Journal of Volgograd State University. History. Area Studies. International Relations, no. 3, pp. 14-24. DOI: 10.15688/jvolsu4. 2016.3.2. (in Russian).

Lyapushkin I.I. (1958). The medieval settlement near Suvorosvkaya village. Archaeological proceedings and research, no. 62, pp. 323-336. (in Russian).

\section{Information about the Author}

Yakov A. Kiyashko, Postgraduate Student, Department of Archaeology, Foreign History and Tourism, Volgograd State University, Prosp. Universitetsky, 100, 400062 Volgograd, Russian Federation, kiyashko.ya@gmail.com, adsi@volsu.ru.

\section{Информация об авторе}

Яков Алексеевич Кияшко, аспирант кафедры археологии, зарубежной истории и туризма, Волгоградский государственный университет, просп. Университетский, 100, 400062 г. Волгоград, Российская Федерация, kiyashko.ya@gmail.com, adsi@volsu.ru.

Citation. Kiyashko Ya.A. (2016). New Objects of Pottery Production on the Suvorovskaya I Site (Excavation Materials of 2012). The Lower Volga Arhaeological Bulletin, vol. 15, no. 1, pp. 137-140. (in Russian). 